\title{
A ARTE E OS LIVROS DIDÁTICOS: A EDUCAÇÃO INDÍGENA EM QUESTÃO.
}

Keyde Taisa da Silva ${ }^{1}$

RESUMO: A escola é um lugar de diversidade, suscetível a episódios de preconceito e discriminação. Nesse sentido, precisa também, ser um lugar de construção de novos conceitos e combate às visões estereotipadas. A legislação educacional brasileira, propõe a inclusão das temáticas étnicas no cotidiano escolar, especialmente com a Lei 11.645/08, que traz a obrigatoriedade da inserção da temática indígena e afrobrasileira nos currículos escolares, especialmente no componente curricular de Arte. Os livros didáticos de Arte voltados para o Ensino Médio, distribuídos pelo MEC são instrumentos importantes para as aulas, enquanto auxiliares do professor numa educação intercultural. Eles apresentam muitas falhas, mas são importantes no processo educativo.

Palavras-Chave: Ensino; Arte; Decolonialidade; Livros didáticos.

\section{THE ART AND THE TEACHING BOOKS: THE INDIGENOUS EDUCATION IN QUESTION.}

ABSTRACT: School is a place of diversity, susceptible to episodes of prejudice and discrimination. In this sense, it must also be a place for the construction of new concepts and the fight against stereotyped views. The Brazilian educational legislation proposes the inclusion of ethnic themes in school daily life, especially with Law 11,645 / 08, which makes it mandatory to include indigenous and Afro-Brazilian themes in school curricula, especially in the Art curriculum component. The high school art textbooks distributed by MEC are important tools for the classes, as teachers' helpers in an intercultural education. They have many flaws, but are important in the educational process.

Keywords: Teaching; Art; Decoloniality; Textbooks.

A escola é um espaço de transmissão de conhecimentos e incentivo ao pensamento crítico/propositivo, onde os estudantes terão, através dos componentes curriculares ministrados, a oportunidade de desenvolver uma série de habilidades e competências que lhes serão úteis por toda a vida. A escola é também o locus de diversidade, onde pessoas das mais variadas etnias se encontram e convivem

\footnotetext{
${ }^{1}$ Mestre em Ciências Sociais e Humanidades pela Universidade Estadual de Goiás. Professora da Educação Básica do Estado de Goiás. E-mail: keyde.silva@seduc.go.gov.br
} 
diariamente, nem sempre de forma muito pacífica, em decorrência de episódios de racismo, preconceito, bullying, entre outras manifestações da intolerância.

Apesar de ser berço de toda essa diversidade, a maioria das escolas não delega, em sua grade curricular, prioridade às questões étnicas, ministrando um ensino massificante, que se baseia quase sempre em materiais didáticos ultrapassados e transmissores de estereótipos de uma versão histórica eurocêntrica. Nesse sentido, um importante passo para a inserção da interculturalidade no seio educacional foi a homologação da Lei de Diretrizes e Bases da Educação Nacional (LDB), no ano de 1996, seguida de outras iniciativas importantes no âmbito da diversidade étnicocultural, como a inclusão da temática nos Parâmetros Curriculares Nacionais (PCNs) como tema transversal.

A alteração da Lei de Diretrizes e Bases, no ano de 2003, através da Lei 10.369/03, e, posteriormente, em 2008, da Lei 11.645/08, explicita a ausência de discussão sobre as raízes do povo brasileiro, sendo necessário a garantia em lei da inserção das temáticas afro-brasileira e indígena, no contexto educativo nacional. Estas leis reforçam a importância da escola no processo de reconhecimento da cultura e valorização das diferenças na constituição da nacionalidade brasileira, mesmo que ainda muito sutilmente.

Tais inserções legais na LDB são concomitantes com o processo de conscientização das etnias brasileiras para luta por direitos, que se fortaleceu a partir da década de 1970, impulsionado pelo surgimento de diversos movimentos organizados, especialmente das etnias indígenas, que "se distingue das inúmeras formas de lutas e resistências dos povos indígenas neste país, que remontam aos primórdios da colonização" (BICALHO, 2010, p.19) Os movimentos se fortalecem inspirados nas teorias decoloniais de valorização da contribuição étnica para a constituição da nação brasileira; e também coincidem com a valorização da disciplina de Arte na escola, que, até então, vinha recebendo papel secundário e com importância reduzida no cenário escolar.

A década de 1970 também desponta nas discussões acerca do colonialismo e da colonialidade. O movimento Modernidade/Colonialidade latino passa a diferenciar esses dois termos a partir das relações de poder, onde o colonialismo se configura como o processo de constituição de uma estrutura de poder que implicou na formação de novas 
relações sociais, que ainda são marcantes na sociedade brasileira. A colonialidade, segundo Mignolo (2003), se reproduz para além da colonialidade, numa dimensão tripla, baseada no poder, no saber e no ser.

O processo decolonial entende que o conhecimento é um instrumento de poder e colonização, portanto, a decolonização passaria necessariamente pela decolonização do saber e do ser, ou seja, da subjetividade. Mignolo (2010, p. 9) diz que "el império marcha hacialas colônias com armas, libros, conceptos e pré-conceptos", ou seja, o conhecimento é um forte instrumento de controle e manipulação, tão forte quanto as armas.

A proposta decolonial têm apresentado possibilidades de reconstrução de histórias silenciadas, subjetividades reprimidas, linguagens e conhecimentos subalternizados; além da potencialização de disciplinas escolares que apresentam possibilidade de reflexão e construção de ideias e conhecimentos críticos entre professores e alunos, como é o caso da disciplina de Arte, a partir dos objetivos já mencionados anteriormente. O princípio da decolonialidade se liga muito diretamente ao conceito de protagonismo. "Protagonizar significa, sobretudo, tornar-se o ator mais importante de algum acontecimento, ato ou fato" (BICALHO, 2010, p. 21). Nesse sentido, decolonizar consiste em proporcionar às etnias subalternizadas, ao longo do tempo, a possibilidade de falar por si só, de serem os atores da sua história.

Corroborando com o conceito de decolonalidade, Antônio Bispo dos Santos, ou, como é conhecido, Negro Bispo - líder quilombola pertencente a uma comunidade rural do Piauí, professor e pesquisador engajado com os movimentos sociais de resistência atuais -, traz um conceito semelhante. $\mathrm{O}$ autor se refere ao termo "contracolonização" em contraposição ao conceito de colonização, pretendendo, assim, "conceituar os processos de enfrentamento entre povos, raças e etnias em confronto direto no mesmo espaço fisico-geográfico" (SANTOS, 2015, p. 20). O conceito foi cunhado a partir da realidade brasileira de povos étnicos em situação de invisibilidade pelos processos históricos e complementa o conceito de decolonialidade.

Nesse sentido, o conceito de contracolonização, cunhado por Nego Bispo, ganha espaço relevante neste estudo, ao lado do conceito de decolonialidade, uma vez que ambos se completam. Enquanto o decolonial busca rever a história a partir da 
assumência de uma postura de luta contínua para escrever uma nova história dos colonizados, agora como atores sociais partícipes do processo, e não como simples agentes moldáveis, submissos e subordinados; o movimento contracolonial parte dos próprios agentes históricos invisibilizados ao longo do tempo.

Numa passagem do texto de Nego Bispo, na qual ele trata da movimentação recente dos contra colonizadores conquistando o direito de se ressignificarem, nos termos designatórios dos povos quilombolas e indígenas na Consituição Federal, o autor enfatiza o acatamento das reinvindicações feitas por esses povos e o que isso significou para as diversas etnias envolvidas. Para ele,

\begin{abstract}
Ao acatarmos essas denominações (quilombo e indígena), por reinvindicação nossa, mesmo sabendo que no passado elas nos foram impostas, nós só o fizemos porque somos capazes de ressignificá-las. Tanto é que elas se transformaram do crime para o direito, do pejorativo para o afirmativo. Isso demonstra um refluxo filosófico que é um resultado direto da nossa capacidade de pensar e de elaborar conceitos circularmente (SANTOS, 2015, p. 95).
\end{abstract}

A contracolonização posta por Nego Bispo é muito atual, tendo em vista o despontamento de movimentos contra coloniais ou decoloniais, ou simplesmente movimentos étnicos de grupos que lutam por seus direitos, a partir da identificação com características que, por muitas vezes, foram renegadas ou acatadas pejorativamente, e que, agora, servem de bandeira de luta. Portanto, o conceito será utilizado ao longo deste artigo, juntamente com o conceito de decolonialismo, uma vez que ambos se complementam e atendem à necessidade da discussão ora proposta.

Seguindo a perspectiva decolonial e contracolonial, e com o intuito de assegurar a discussão da temática indígena e negra no âmbito escolar, a aprovação da Lei $11.645 / 08$ foi um marco importante, uma vez que traz a obrigatoriedade do ensino da história e da cultura afrobrasileira e indígena em sala de aula, dando ênfase nos componentes de Arte, Literatura e História. A necessidade de ter uma legislação que obrigue a discussão de temas que deveriam ser rotineiros no cotidiano brasileiro, dada a nossa descendência heterogênea, suscita opiniões divergentes, mas o fato é que a legislação representa um ponto positivo na luta dos grupos étnicos em prol do seu reconhecimento. 
A ênfase dada à disciplina de Arte nessa legislação remonta, não sem o recebimento de duras críticas por diversos segmentos, à capacidade que ela possui de trabalhar com a diversidade cultural através da pluralidade da própria linguagem, sendo capaz de desenvolver culturalmente e ampliar a contextualização do estudante através do uso de diversos códigos artísticos. As artes possuem capacidade de mobilizar a expressão e a comunicação dos estudantes, dando suporte à função da escola de formar cidadãos e valorizar diferenças culturais e étnicas.

Nesse sentido, a intencionalidade da legislação é a garantia daquilo que Boaventura de Souza Santos (2006) enfatiza, dizendo que "temos o direito a ser iguais, sempre que a diferença nos inferioriza; temos o direito de ser diferentes sempre que a igualdade nos descaracteriza" (Idem, p. 462). A legislação visa a garantia da manutenção da diferença indígena enquanto grupos diversos, com características próprias, com cultura específica; mas, também, da igualdade dos mesmos, enquanto cidadãos brasileiros, dignos de respeito e direitos, e uma educação intercultural é o caminho para que esse reconhecimento aconteça de forma natural, desde que seja realmente oferecida "uma educação para o reconhecimento do 'outro', para o diálogo entre os diferentes grupos sociais e culturais" (CANDAU, 2008, p. 52)

Nesse processo de reconhecimento e valorização dos grupos étnicos, especialmente da diversidade de povos indígenas que habitam nosso país, a educação possui papel de destaque, mesmo que ainda não tenha desenvolvido características fundamentais para assumir sua função de negociadora cultural, que, segundo Vera Candau (2008, p. 52),

... enfrenta os conflitos provocados pela assimetria de poder entre os diferentes grupos socioculturais nas nossas sociedades e é capaz de favorecer a construção de um projeto comum, pelo qual as diferenças sejam dialeticamente integradas. A perspectiva intercultural está orientada à construção de uma sociedade democrática, plural, humana, que articule políticas de igualdade com políticas de identidade.

Considerando a educação para a interculturalidade, outro avanço significativo nesse sentido foi a homologação da Base Nacional Comum Curricular, que prevê um ensino voltado para o desenvolvimento de competências e habilidades nos estudantes durante seu tempo de escolaridade. Entre estas competências principais, algumas delas 
estão ligadas diretamente ao convívio social dos indivíduos e requer que cada estudante seja capaz de elencar conhecimentos teóricos para resolver situações reais do seu cotidiano, e, especialmente, compreenda o contexto cultural no qual está inserido.

A primeira das dez competências gerais da BNCC diz que o estudante precisa ser capaz de valorizar e utilizar "os conhecimentos historicamente construídos sobre o mundo físico, social, cultural e digital para entender e explicar sobre a realidade, continuar aprendendo e colaborar para a construção de uma sociedade justa, democrática e inclusiva" (BRASIL, 2018, p.10-11). Nesse sentido, é preciso que ele compreenda o passado para, a partir de então, construir um futuro mais justo e democrático, reconhecendo o valor de todos os agentes envolvidos na formação da sociedade brasileira, tanto no passado, quanto no presente. A nona competência se liga diretamente ao convívio social dos estudantes, quando diz que deverão ser capazes de, ao final do Ensino Médio,

9. Exercitar a empatia, o diálogo, a resolução de conflitos e a cooperação, fazendo-se respeitar e promovendo o respeito ao outro e aos direitos humanos, com acolhimento e valorização da diversidade de indivíduos e de grupos sociais, seus saberes, identidades, culturas e potencialidades, sem preconceitos de qualquer natureza (BRASIL, 2018, p.10-11).

Sendo assim, para que o estudante possa respeitar as diversas identidades, culturas e saberes, ele precisa conhecer sobre essa diversidade e esse conhecimento só acontecerá através da mediação do professor, que precisa ser consciente da importância de se colocar em prática o que é garantido por lei a respeito da diversidade étnica e cultural no âmbito escolar.

Os documentos orientadores abrem caminhos para a prática de um processo de ensinagem $^{2}$ contracolonial,sendo necessário apenas que professores e autoridades educadoras se voltem para tais práticas e valorizem a investigação e a criação de uma abordagem problematizadora no trato com as questões étnicas em sala de aula, ao invés de reproduzir discursos saturados e perpetuados através de materiais didáticos parciais e preconceituosos.

\footnotetext{
${ }^{2}$ Ensinagem é o termo cunhado por Léa das Graças Camargo Anastasiou, em 1994, para se referir a uma prática social, crítica e complexa em educação, entre professor e estudante, "englobando tanto a ação de ensinar quanto a de apreender" (ANASTASIOU; ALVES, 2005, p. 15), dentro ou fora da sala de aula. 
Para auxiliar os educadores na tarefa de fazer uma educação voltada para as questões étnicas e interculturais, alguns instrumentos podem ser utilizados de forma eficaz, abrindo margem para a garantia do que é preconizado pela legislação vigente. $\mathrm{O}$ primeiro instrumento disponível ao professor, em qualquer unidade escolar, são os componentes curriculares e seus currículos básicos. Entre os componentes que compõem o currículo mínimo que o estudante precisa receber ao longo de sua formação escolar, o de Arte, em especial, traz em sua ementa algumas possibilidades, como a formação do pensamento crítico e propositivo da imaginação e da expressão por meio de imagens, gestos e movimentos.

A Arte no Ensino Médio está inserida na área de conhecimento Linguagens, códigos e suas tecnologias, ao lado de Língua Portuguesa, Língua Estrangeira Moderna, Educação Física e Informática, portanto, ela é considerada, pelos Parâmetros Curriculares Nacionais (PCNs), do Ensino Médio, como um tipo de linguagem utilizada pelo ser humano para se expressar. Segundo o documento, "a linguagem é considerada aqui como a capacidade humana de articular significados coletivos e compartilhá-los, em sistemas arbitrários de representação, que variam de acordo com as necessidades e experiências da vida em sociedade" (BRASIL, 2000, p. 5). Sobre a importância da linguagem, o documento ainda acrescenta:

\footnotetext{
A linguagem permeia o conhecimento e as formas de conhecer, o pensamento e as formas de pensar, a comunicação e as formas de comunicar, a ação e os modos de agir. Ela é a roda inventada, que movimenta o homem e é movimentada pelo homem. Produto e produção cultural, nascida por força das práticas sociais, a linguagem é humana e, tal como o homem, destaca-se pelo caráter criativo, contraditório, pluridimensional, múltiplo e singular a um só tempo (BRASIL, 2000, p. 5).
}

Apesar de ser considerada uma linguagem importante pelos documentos, é perceptível, historicamente, um certo descaso da instituição escola com a Arte e seus conhecimentos, pois, segundo o próprio PCN,

\footnotetext{
Observando a nossa história de ensino e aprendizagem de Arte na Escola Média, nota-se um certo descaso de muitos educadores e organizadores escolares, principalmente no que se refere à compreensão da Arte como um conhecimento humano sensível-cognitivo, voltado para um fazer e apreciar artísticos e estéticos e para uma reflexão sobre sua história e contextos na sociedade humana (BRASIL, 2000, p. 46).
} 
Essa supressão da importância da Arte na escola média perdura até a década de 1980, quando começam a surgir movimentos organizados por arte-educadores, novos posicionamentos sobre o ensino de arte, que refletem diretamente nos cursos de formação em arte-educação, iniciados na Universidade de São Paulo e difundidos pelo país. Essa movimentação originou uma luta para a inserção da arte nos currículos das escolas de Educação Básica no Brasil; assim como também para que ela fizesse parte da Lei de Diretrizes e Bases da Educação Nacional, de 1996, Lei no 9.394 (Art. 26, § 2º) (BRASIL, 2000, p. 47).

As características sociais da arte se tornaram, então, essenciais para sua abordagem em sala de aula, uma vez que, através de práticas de produção e apreciação artística e de reflexão, proporcionadas pelo professor, os estudantes podem compreender e envolver-se em posições estéticas e apropriar-se de saberes culturais contextualizados.

A compreensão de processos históricos e culturais através de manifestações artísticas, assimiladas durante as aulas, que podem se basear nos campos da arte Música, Artes Visuais, Dança, Teatro e Artes Audiovisuais, entre outras - são capazes de favorecer a formação identitária e cidadã do jovem que se forma na escola de Ensino Médio, fecundando a consciência de uma sociedade multicultural, na qual ele confrontará seus valores, crenças e competências culturais na realidade em que se insere (BRASIL, 2000, p. 48).

O ensino de arte na escola se baseia no intuito de capacitar os estudantes a desenvolver sua sensibilidade e agir como "cidadãos inteligentes, sensíveis, estéticos, reflexivos, criativos e responsáveis, no coletivo, por melhores qualidades culturais na vida dos grupos e das cidades, com ética e respeito pela diversidade" (BRASIL, 2000, p. 50). Os objetivos deste componente, descritos nos Parâmetros Curriculares Nacionais e com vistas ao pluriculturalismo brasileiro, são bastante enfáticos e refletem a sua importância para a superação de desigualdades e preconceitos históricos, uma vez que a própria escola ajudou, ao longo dos séculos, a perpetuá-los. Entre estes objetivos, podemos destacar alguns:

Promover o entendimento de cruzamentos culturais pela identificação de similaridades, particularmente nos papéis e funções da arte, dentro e entre grupos culturais; reconhecer e celebrar a diversidade étnica e cultural em arte 


\begin{abstract}
e em nossa sociedade, enquanto também se potencializa o orgulho pela herança cultural em cada indivíduo, seja ela resultante de processos de erudição ou de vivências do âmbito popular, folclórico ou étnico; possibilitar problematizações acerca do etnocentrismo, estereótipos culturais, preconceitos, discriminação e racismo nas ações que demarcam os eixos da aprendizagem; enfatizar o estudo de grupos particulares e/ou minoritários (do ponto de vista do poder) como mulheres, índios e negros; possibilitar a confrontação de problemas, como racismo, sexismo, excepcionalidade física ou mental, participação democrática, paridade de poder; examinar a dinâmica de diferentes culturas e os processos de transmissão de valores; desenvolver a consciência acerca dos mecanismos de manutenção da cultura dentro de grupos sociais; questionar a cultura dominante, latente ou manifesta e todo tipo de opressão; destacar a relevância da informação para a flexibilização do gosto e do juízo acerca de outras culturas (BRASIL, 1998, p. 42).
\end{abstract}

Nesse sentido, a disciplina de Arte na escola propõe a criação de salas de aula como ambientes investigadores, ou seja, ambientes que despertem no estudante a curiosidade e que o leve a pesquisar e problematizar temáticas diversas. Segundo Demo, a base da educação escolar é a pesquisa, pois quem conhece é capaz de intervir de forma competente, crítica e inovadora:

\begin{abstract}
Não é possível sair da condição de objeto (massa de manobra), sem formar consciência crítica desta situação e contestá-la com iniciativa própria, fazendo deste questionamento o caminho de mudança. Aí surge o sujeito, que o será tanto mais se, pela vida afora, andar sempre de olhos abertos, reconstruindo-se permanentemente pelo questionamento. Nesse horizonte, pesquisa e educação coincidem, ainda que no todo, uma não possa reduzir-se à outra (DEMO, 2007, p. 8).
\end{abstract}

Incentivar a pesquisa acerca das culturas presentes no Brasil e compartilhadas pelos estudantes precisa ser o papel das disciplinas ministradas durante toda a educação básica, incluindo a disciplina de Arte, através de uma abordagem pluriculturalista, que não significa apenas inserir na cultura dominante características de outras culturas, mas problematizar a realidade cultural atual a partir de diversas outras realidades que a originaram, e levar os estudantes a perceber que a diversidade faz parte da origem do povo brasileiro. Porém, esta ainda não é uma realidade presente na maioria das escolas brasileiras, o que pode ser comprovado pela análise da legislação sobre educação do país.

As unidades escolares enfrentam, diariamente, uma série de empecilhos no processo de construção de uma educação pluricultural, a partir de uma realidade preconceituosa e estigmatizadora, que cria estereótipos difíceis de serem revertidos. A 
inserção de um debate problematizador no ambiente escolar se finca em uma preparação adequada dos docentes para mediar essas situações em sala de aula; e o que muitas vezes presenciamos na escola pública, são docentes que não possuem formação na área de atuação, e que, por vezes, desconhecem a legislação que rege o processo educacional, além de trabalhar com materiais didáticos limitados, que acabam se tornando a única fonte de pesquisa para o planejamento das aulas; entre outras tantas situações dificultadoras do processo.

\section{OS LIVROS DIDÁTICOS E A LEI 11.645/08}

Quanto aos livros didáticos utilizados pelos docentes no componente de Arte, nas escolas públicas, eles foram distribuídos pelo Ministério da Educação (MEC), através do Programa Nacional do Livro Didático (PNLD), pela primeira vez no ano de 2015, portanto, alguns anos após a homologação da Lei 11.645/08 elaborados à luz do que preconiza a legislação. Nesse sentido, já na parte introdutória do Guia de Livros Didáticos PNLD 2014 do Ensino Médio, do componente de Arte, o professor se depara com uma situação controversa, uma vez que o texto cita a LDB, mas ignora a importância do componente para a Lei 11.645/08.

Estabelecendo-se como disciplina obrigatória no ano de 1996, com a Lei de Diretrizes e Bases da Educação Nacional/LDB n.9.394/96, o componente curricular Arte congrega, no ensino fundamental, os campos artísticos das Artes Visuais, Dança, Música e Teatro e, no ensino médio, acrescentam-se as Artes Audiovisuais (BRASIL, 2014, p. 08).

O documento cita ainda o objetivo do componente curricular de Arte na Educação Básica, mas não se refere, em nenhum momento, ao atendimento legal específico. Segundo o Guia,

Na Educação Básica, o componente curricular Arte tem como objetivo viabilizar experiências significativas de produção, fruição e reflexão artística. A experiência aqui referida é aquela que ocorre na relação entre o sujeito e os demais, entre o sujeito e o ambiente escolar, que valoriza o processo de aprendizagem, que demanda, necessariamente, cognição e emoção. Nesse processo, o professor é coparticipante da experiência, devendo não somente viabilizá-la, mas compartilhá-la com os alunos (BRASIL, 2014, p. 08). 
Um pouco mais a frente, falando sobre a elaboração dos livros disponibilizados, o Guia menciona que os professores poderão encontrar nesses materiais as produções indígenas e afro-brasileiras de forma contextualizada, e não apenas como integrantes do passado. "Ressaltamos que deverão ser contempladas as manifestações artístico-culturais brasileiras, destacando as produções indígenas e de afrodescendentes, não só as de gerações passadas, mas também as produções contemporâneas" (BRASIL, 2014, p. 10).

O Guia traz ainda, uma série de questões que norteiam a análise a ser feita pelo professor quanto aos materiais disponibilizados e, entre elas, está uma questão que se refere à legislação vigente que deve ser observada, ao mencionar a lei 11.645/08, em seu artigo 26 e incisos 10 e 20, que diz que:

Art. 26-A. Nos estabelecimentos de ensino fundamental e de ensino médio, públicos e privados, torna-se obrigatório o estudo da História e Cultura Afrobrasileira e Indígena.

- $\S 1$ o O conteúdo programático a que se refere este artigo incluirá diversos aspectos da história e da cultura que caracterizam a formação da população brasileira, a partir desses dois grupos étnicos, tais como o estudo da História da África e dos africanos, a luta dos negros e dos povos indígenas no Brasil, a cultura negra e indígena brasileira e o negro e o índio na formação da sociedade nacional, resgatando as suas contribuições nas áreas social, econômica e política, pertinentes à História do Brasil.

- 20 Os conteúdos referentes à história e cultura afro-brasileira e dos povos indígenas brasileiros serão ministrados no âmbito de todo o currículo escolar, em especial nas áreas de educação artística e de literatura e história brasileiras (BRASIL, 2014, p. 17).

Já no Guia da segunda escola, em 2017, aborda a questão da cidadania multicultural e a importância da escola como promotora da interação cultural. Segundo o documento,

Sendo a Arte parte integrante da cultura, salienta-se que sua incorporação nas escolas é via fundamental para a construção da cidadania multicultural, já que ela proporciona reconhecimento e respeito à diversidade cultural e pessoal dos estudantes, uma vez que o ensino/aprendizagem em Arte se concretiza mediante experiência que coaduna produção, reflexão e fruição. É através da Arte que o estudante constrói conhecimentos dimensionados à sua realidade, seu desenvolvimento pessoal e seu contexto cultural (BRASIL, 2017, p. 6/7). 
No guia atual, a única referência à educação intercultural, ou multicultural, é a passagem acima citada, sendo que os textos introdutórios são bastante suscintos, porém, nas resenhas das obras há sempre a menção à questão cultural a ser abordada, ao longo dos capítulos, nos livros didáticos das coleções. Porém, não traz, como no guia anterior, o referencial legal ao qual o professor deve se ater. Desse modo, o professor precisará de muita atenção e um conhecimento prévio a fim de fazer uma boa escolha, ciente do que deverá ser observado no processo de análise dos livros disponibilizados pelas editoras para as escolas. Em muitos casos, são escolhidos aqueles materiais que mais se aproximam dos aspectos desejados, já que nenhum deles consegue atender à totalidade das exigências legais.

Para o primeiro processo de escolha dos livros do componente de Arte para o Ensino Médio, ocorrido em 2014, validado para o triênio 2015/2017, foram disponibilizadas duas coleções: Por Toda PARTE e Arte em Interação. Já para a segunda escolha, ocorrida no ano de 2017, com validade para o triênio 2018/2020, contou com a disponibilidade de cinco coleções diferentes: Todas as Artes; Percurso da Arte; Arte em Interação; Arte por Toda PARTE e Arte de Perto.

A presente pesquisa se aterá em apenas dois livros didáticos, considerando que são apresentados em volume único: um livro que pertenceu à primeira escolha e que já está na segunda edição: Arte por Toda PARTE; e um livro que está em sua primeira edição: Arte de Perto, participando do processo de escolha pela primeira vez. A intenção da pesquisa é perceber como ambos abordam a questão cultural indígena, em atendimento à Lei 11.645/08, e compreender se há diferenças nestas abordagens.

\section{COLEÇÃO ARTE POR TODA PARTE}

O livro Arte por Toda PARTE, segundo a sua resenha no Guia 2017, enfatiza a preocupação dos autores em abordar os campos artísticos de forma integrada, perpassando, em cada capítulo, todos os campos. A diversidade cultural é abordada, de forma geral, no decorrer dos textos e capítulos, porém, a cultura indígena não é abordada de forma satisfatória em temas que poderiam ser melhor explorados, como a arte corporal, danças, entre outras temáticas. Os textos da resenha não mencionam a necessidade de atendimento à legislação ou à educação multicultural. 
$\mathrm{Na}$ obra em si, poucas vezes são mencionadas as temáticas indígenas. A primeira menção às produções indígenas se dá no quarto capítulo, intitulado de Matérias da Arte, onde a relação entre o corpo e arte é abordada em uma seção específica. Em uma parte denominada de Conexões, os autores trazem a relação entre a arte e a pluralidade cultural. É enfatizado o processo de pintura corporal dos indígenas, ilustrado com a imagem de um indígena da etnia Kalapalo, adornado para a festividade do Djawari, informação constante na legenda da imagem.

O texto se inicia com um trecho da Carta de Pero Vaz de Caminha, relatando os enfeites utilizados pelos povos com quem ele se deparou ao chegar ao território brasileiro. Utiliza-se também das palavras de Darcy Ribeiro (1995), na obra O Povo Brasileiro, ao destacar a "necessidade de beleza" que os indígenas possuem, enfatizando que cada povo possui uma noção em relação ao que é belo ou útil e que cada etnia possui símbolos e signos diferentes, com significações distintas entre si, característica da diversidade cultural desses povos.

O texto, que ocupa uma página do livro, é baseado em conceitos de terceiros a respeito do que os indígenas sentem e pensam sobre os adornos, as pinturas e o que representam para eles, de forma que não se traz nenhuma fala indígena a respeito da temática, como se eles precisassem de tradução ou de porta-voz para externar sua cultura.

A segunda aparição da temática indígena acontece ainda no mesmo capítulo, e ocupa duas páginas do livro, na mesma seção denominada de Conexões. Dessa vez, a abordagem se refere à pluralidade cultural dos povos indígenas e é ilustrada por imagens de cestaria e pintura corporal, com uma única legenda, ao se referir aos "desenhos em padrão compostos por elementos iguais que se repetem sequencialmente ou periodicamente" (UTARI et.al, 2016, p. 186), sem mencionar a qual etnia pertencem os grafismos. Há ainda, na mesma página, a imagem de uma boneca Ritxoko, tradicional entre os indígenas da etnia Karajá, e que aparece na imagem com a legenda dizendo apenas que é uma "cerâmica karajá representando a pintura corporal e o penteado tradicional as indígenas Karajá” (UTARI et.al, 2016, p. 186).

O texto que acompanha as imagens não cita, em nenhum momento, nenhuma etnia em referência às imagens ilustrativas, e diz pouco sobre a diversidade cultural indígena, mencionando apenas que 


\begin{abstract}
As culturas indígenas criam padronagens geométricas, com grafismos simbólicos inspirados na natureza e com base em seu universo mitológico. São imagens que os povos indígenas aprendem a ver, interpretar e criar. Assim, cada grupo cultural pode atribuir significados simbólicos diferentes para cada desenho das padronagens que criam (UTARI et.al, 2016, p. 188).
\end{abstract}

Na página seguinte, há a proposição de uma atividade, onde os estudantes devem criar padronagens inspiradas na natureza. A atividade está ilustrada com uma imagem de praticamente meia página, lembrando os grafismos indígenas, com a legenda que diz que "os indígenas realizam diversos estudos de desenhos em padronagens antes de realizar suas pinturas e fabricar produtos artesanais" (UTARI et.al, 2016, p. 189), mas não se refere à que etnia esses desenhos ilustrados pertencem ou que tipo de simbologia eles assumem para os povos que o criaram.

Ao final do capítulo 6, para os estudantes, há a última menção à temática indígena, em um infográfico que ocupa duas páginas do livro e traz uma série de assuntos resumidos e bastante ilustrados. A seção é intitulada Bem Indígena, seguida da seguinte introdução: “As culturas e as artes dos povos indígenas brasileiros fazem parte do Patrimônio Cultural do Brasil. Esses direitos foram conquistados com muita luta de grupos indígenas, organizações e profissionais que estudam e defendem a valorização desses povos" (UTARI et.al 2016, p. 306).

A seção aborda os bens materiais indígenas, citando os acervos guardados em museus, os sítios arqueológicos e os lugares sagrados. Na parte destinada aos bens imateriais estão a língua, música, danças e cantos, cultura e imaginário, além da cestaria. Todos estes bens, tanto materiais quanto imateriais, são colocados de forma genérica, sem enfatizar nenhum povo em especifico. São citados também dois patrimônios imateriais de forma específica: a arte Kusiwa, que, segundo o texto, é uma técnica de pintura corporal e arte gráfica da população Wajãpi e é considerada como Patrimônio Cultural Imaterial brasileiro; e a arte de fazer as bonecas Karajás, conhecidas como Ritxòkò, também considerado como patrimônio imaterial.

O infográfico é bastante chamativo, pelas ilustrações e por algumas informações constantes, porém, continua na vertente de ter alguém falando pelos indígenas. Não traz nenhuma fala étnica, nenhuma participação de indígena, numa época onde presenciamos tantos artistas e autores indígenas produzindo obras literárias, 
entre os quais artísticas de expressão nacional. Esse fato denota uma visão bastante restrita dos autores, que perdem oportunidades de fazer uma contextualização étnica nas temáticas artísticas abordadas ao longo do livro didático.

No livro destinado ao uso do professor, em uma seção específica denominada de "Dialogando com o professor", consta um pequeno texto intitulado de "História e cultura indígenas na escola" (p. 330), no qual os autores trazem um pouco sobre a diversidade indígena no Brasil e a importância de os sistemas educacionais inserirem tais temáticas em sala de aula, salientando a importância do professor no papel de reinventar o cotidiano escolar, especialmente no componente de Arte; e também sobre as potencialidades do trabalho transdisciplinar, com a busca de parcerias para enriquecer as aulas ministradas, com o intuito de alcançar os objetivos de formação dos estudantes, contribuindo "para a reflexão sobre o ser humano e sua atuação política, histórica e social, que produz e reinventa linguagens e sistemas simbólicos" (UTARI et.al, 2016, p. $331)$.

\section{COLEÇÃO ARTE DE PERTO}

A coleção Arte de Perto, que também é apresentada em volume único para o Ensino Médio, traz, em sua resenha, a proposta de trabalhar com a arte contemporânea permeando todos os capítulos. A distribuição dos conteúdos no livro é feita a partir de capítulos com temáticas específicas, e o capítulo 15 é destinado à discussão acerca da cultura ou das culturas brasileiras. O capítulo se inicia na página 234 e é ilustrado com uma foto onde aparece um casal indígena registrando um momento através da câmera do celular. A legenda diz que a foto é de

\footnotetext{
indígenas da etnia Kuikuro, do Alto Xingu, registrando com smartphones a competição de cabo de força no I Jogos Mundiais dos Povos Indígenas, realizado em Palmas (TO), que contou com a presença e participação de povos indígenas de diversos países como: Argentina, Bolívia, Canadá, Chile, Mongólia, Rússia, entre outros. Foto de outubro de 2015 (ROCHA et.al 2016, p. 234).
}

As próximas 13 páginas do capítulo são dedicadas à discussão sobre cultura, capital cultural, relação entre cultura e juventude e atividades inerentes à temática. $\mathrm{Na}$ 
página 248, a discussão acerca da composição da cultura brasileira é retomada ao se abordar a contribuição afro-brasileira para a composição do que é chamado de "Culturas Brasileiras" pelos autores e compõem o capítulo 16, entre textos e atividades que se estendem até a página 264.

No capítulo 17 , que se inicia na página 265, a temática abordada é a musicalidade como forma de imaginar e experimentar o mundo. Logo após o título, há uma citação do indígena Davi Kopenawa, Yanomami, que diz que

\footnotetext{
Nós, habitantes da floresta, não maltratamos a Terra. Não desmatamos a floresta sem medida. Toda essa destruição não é nossa marca, é a pegada dos brancos, o rastro de vocês na terra. É isso que queremos falar. Os brancos carecem de sabedoria e não pensam muito longe (ROCHA et.al 2016, p. 265).
}

Logo abaixo da epigrafe, uma imagem de indígenas caracterizados para o festival MaririYawanawá, que, segundo a legenda da foto, é uma "tradição indígena que envolve festas, brincadeiras e cultura, e celebra o sentimento de preservação da natureza, realizado na Aldeia Mutum, da Terra Indígena (TI) do Rio Gregório"(ROCHA et.al 2016, p. 265). O texto descreve a participação da dança nos rituais de diferentes culturas e enfatiza a valorização que os povos indígenas dão à esses rituais e suas danças.

Basicamente o capítulo se dedica à dança do Turé, dança típica dos povos indígenas do baixo do Rio Oiapoque, na fronteira do Brasil com a Guiana Francesa. As etnias que praticam tal ritual são citadas pelos autores: Palikur, Galibi-Marworno, Galibi-Kali'na e Karipuna; que explicam o ritual do Turé, que é uma festa tradicional realizada para os espíritos do Outro Mundo em retribuição às curas feitas por intermédio dos pajés, e para se comunicar com os espíritos - Karuãna. As próximas sete páginas do capítulo (267-274) são dedicadas à temática do Turé.

No próximo capítulo, 18, a temática abordada é a "visualidade das artes indígenas brasileiras" e a epígrafe é uma fala do antropólogo Darcy Ribeiro sobre o que é arte índia. A imagem que ilustra o início do capítulo é de uma mulher indígena da etnia Kayapó, da aldeia Moykarakô, pintando em tecido uma figura geométrica. As próximas nove páginas exploram bastante a riqueza artística de diversos povos indígenas e em bases variadas. Desde a pintura em tecido, que é algo mais 
contemporâneo para os indígenas, até as tradicionais pinturas corporais. Nesse capítulo, a riqueza étnica dos povos indígenas é mais explorada, sendo utilizadas imagens de vários deles para ilustrar os textos.

A primeira ilustração é de um banco com características retiradas de animais, denominado de zoomórfico, dos povos Mehinako, do Alto Xingu. Em seguida, grafismos Kayapó e uma pintura corporal dos Barasana, de Manaus. Os arranjos e adornos são ilustrados por uma foto de um colar de penas dos Boe Bororo, do Mato Grosso. Uma cerâmica do povo Asurini, do Alto Xingu e uma pintura corporal feita por indígenas Kayapó do Mato Grosso e Pará também é apresentada.

Nessas páginas há a ênfase na caracterização da arte indígena enquanto manifestação artística através da cerâmica e dos grafismos. As próximas páginas se dedicam à arte plumária, cestaria e cerâmica de povos como os Guarani Kaiowá, do Mato Grosso do Sul; máscaras e cerâmica dos povos Kayapó, do Pará e Karajá, de Goiás, Tocantins e Mato Grosso; e a cestaria dos povos Wajãpi do Amapá. Na página 283 há um depoimento do indígena Almires Martins, do povo Guarani, sobre a invisibilidade dos povos indígenas e as dificuldades enfrentadas por eles para sobreviver.

Portanto, na coleção, a temática indígena e cultural se concentra nos capítulos 15 ao 18, onde há a menção de uma série de etnias diferentes e às produções artísticas desses povos, mesmo que ainda traga a imagem indígena atrelada à vida nas aldeias, com exceção da primeira imagem que abre os capítulos, onde os indígenas utilizam o celular, numa menção à inserção desses povos no cotidiano social contemporâneo. Outro fator que destaca a abordagem dessa coleção à temática indígena, é a presença, mesmo que ainda tímida - em apenas uma passagem - da fala do próprio indígena sobre a sua vida, e não de alguém falando por ele.

O livro, certamente, perde boas oportunidades de contextualizar a presença indígena no contexto social, nas músicas e outras expressividades artísticas e/ou cotidianas, nas cidades, fazendo atividades que antes não eram realizadas por indígenas, mas já representa um avanço em comparação à coleção que foi elaborada para a escola anterior e analisada na presente pesquisa, que restringe a temática indígena a apenas algumas menções ao longo do livro todo. 
Esse cenário, de pouca inserção da temática indígena nos livros didáticos, mesmo que os autores reconheçam a importância de tais abordagens em sala de aula, comprovadas pelos textos de apoio presentes no manual do professor, a forma como é apresentado ao longo dos capítulos ainda é incipiente, e não atende ao que é preconizado pela Lei 11.645/08, que já está em vigor há mais de onze anos e ainda não conseguiu ser atendida em sua plenitude nas salas de aula; em especial no que concerne ao componente de Arte, o que pode ser comprovado pelos materiais didáticos analisados e disponíveis para uso dos docentes.

Nesse sentido, a preparação do professor para ministrar as aulas de Arte é fundamental, uma vez que o senso crítico e o conhecimento da legislação é que vai determinar a maneira que o professor abordará as temáticas étnicas em suas aulas. Se ele é conhecedor do que preconiza a legislação, sabe das obrigatoriedades trazidas por ela, certamente utilizará outros recursos disponíveis para elaborar e ministrar suas aulas numa perspectiva decolonial e contra colonial. Atualmente, a gama de informações e materiais, inclusive de autoria de indígenas, disponíveis e ao alcance do professor na Internet, é muito rica; o que abre possibilidades de enriquecer a prática cotidiana e instigar nos alunos a curiosidade para buscar novos conhecimentos e, assim, romper com preconceitos há muito arraigados.

\section{BIBLIOGRAFIA}

ANASTASIOU, L. G. C.; ALVES, L. P. (Org.). Processos de ensinagem na universidade: pressupostos para as estratégias de trabalho em aula. 5. ed. Joinville, SC: UNIVILLE, 2005.

BRASIL. Lei n. ${ }^{\circ}$ 9.394, de 20 de dezembro de 1996. Estabelece as diretrizes e bases da educação nacional. Diário Oficial [da] República Federativa do Brasil, Poder Executivo, Brasília, DF, 23 dez. 1996, v. 134, n. 248, Seção I, p. 27.834-27.841.

BRASIL. Secretaria de Educação Fundamental. Parâmetros curriculares nacionais: arte. Secretaria de Educação Fundamental. - Brasília : MEC / SEF, 1998.

BRASIL. Lei n. 11.645, de 10 março de 2008. Diário Oficial da República Federativa do Brasil, Poder Executivo, Brasília, DF, 11 mar. 2008.

BRASIL. Parâmetros Curriculares Nacionais. Bases Legais, Brasília: MEC. 2000. 
BRASIL. Governo Federal. Base Nacional Comum Curricular: Fundamentos Pedagógicos e Estrutura Geral da BNCC: versão final, Brasília, 2018. Disponível em <http://download.basenacionalcomum.mec.gov.br/>. Acesso em: 10 de jan. 2019.

BRASIL. Secretaria de Educação Básica. Guia de livros didáticos: PNLD 2014: Arte. Brasília: MEC, 2014.

BRASIL. Secretaria de Educação Básica. Guia de livros didáticos: PNLD 2017: Arte. Brasília: MEC, 2017.

BICALHO, Poliene S. S. Protagonismo indígena no Brasil: movimento, cidadania e direitos (1970-2009). Tese (Doutorado) - Instituto de Ciências Humanas, Departamento de História, Universidade de Brasília, Brasília, 2010. Disponível em: $<$ http://repositorio.unb.br/bitstream/10482/6959/1/2010_PolieneSoaresdosSantosBicalh o.pdf>

CANDAU, V. M. Direitos humanos, educação e interculturalidade: as tensões entre igualdade e diferença. Revista Brasileira de educação, v.13, n 37 jan/abr.2008.

DEMO, Pedro. Educar Pela Pesquisa. 8 ed. Campinas: Autores Associados, 2007.

MIGNOLO, W. Histórias locais/projetos globais: colonialidade, saberes subalternos e pensamento liminar. Tradução de Solange Ribeiro de Oliveira. Belo Horizonte, Ed. UFMG, 2003.

- Desobediencia epistémica: retórica de lamodernidad, lógica de la colonialidad y gramática de la descolonialidad. Argentina: Ediciones del signo, 2010.

UTARI et.al. Por toda PARTE: Arte: Ensino Médio. $2^{\circ}$ ed. - São Paulo: FTD, 2016.

RIBEIRO, Darcy. O Povo Brasileiro: A formação e o sentido de Brasil. $2^{\mathrm{a}}$ ed. São Paulo: Companhia das Letras, 1995.

ROCHA, M. A. et.al. Arte de Perto. Ensino Médio. $1^{\text {o }}$ ed. - São Paulo: Leya, 2016.

SANTOS, B. S. A construção intercultural da igualdade e da diferença. In: SANTOS, B. S. A gramática do tempo. São Paulo: Cortez, 2006. p. 279-316.

SANTOS, Antônio Bispo. Colonização, Quilombos: modos e significações. Brasília, 2015. 